NASA/TM-2006-214262

Flight Development for Cryogenic Fluid Management in Support of Exploration Missions

David J. Chato

Glenn Research Center, Cleveland, Ohio 


\section{NASA STI Program . . . in Profile}

Since its founding, NASA has been dedicated to the advancement of aeronautics and space science. The NASA Scientific and Technical Information (STI) program plays a key part in helping NASA maintain this important role.

The NASA STI Program operates under the auspices of the Agency Chief Information Officer. It collects, organizes, provides for archiving, and disseminates NASA's STI. The NASA STI program provides access to the NASA Aeronautics and Space Database and its public interface, the NASA Technical Reports Server, thus providing one of the largest collections of aeronautical and space science STI in the world. Results are published in both non-NASA channels and by NASA in the NASA STI Report Series, which includes the following report types:

- TECHNICAL PUBLICATION. Reports of completed research or a major significant phase of research that present the results of NASA programs and include extensive data or theoretical analysis. Includes compilations of significant scientific and technical data and information deemed to be of continuing reference value. NASA counterpart of peer-reviewed formal professional papers but has less stringent limitations on manuscript length and extent of graphic presentations.

- TECHNICAL MEMORANDUM. Scientific and technical findings that are preliminary or of specialized interest, e.g., quick release reports, working papers, and bibliographies that contain minimal annotation. Does not contain extensive analysis.

- CONTRACTOR REPORT. Scientific and technical findings by NASA-sponsored contractors and grantees.
- CONFERENCE PUBLICATION. Collected papers from scientific and technical conferences, symposia, seminars, or other meetings sponsored or cosponsored by NASA.

- SPECIAL PUBLICATION. Scientific, technical, or historical information from NASA programs, projects, and missions, often concerned with subjects having substantial public interest.

- TECHNICAL TRANSLATION. Englishlanguage translations of foreign scientific and technical material pertinent to NASA's mission.

Specialized services also include creating custom thesauri, building customized databases, organizing and publishing research results.

For more information about the NASA STI program, see the following:

- Access the NASA STI program home page at http://www.sti.nasa.gov

- E-mail your question via the Internet to help@sti.nasa.gov

- Fax your question to the NASA STI Help Desk at 301-621-0134

- Telephone the NASA STI Help Desk at 301-621-0390

- Write to:

NASA STI Help Desk

NASA Center for AeroSpace Information 7121 Standard Drive Hanover, MD 21076-1320 


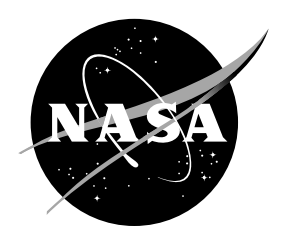

\section{Flight Development for Cryogenic Fluid Management in Support of Exploration Missions}

David J. Chato

Glenn Research Center, Cleveland, Ohio

Prepared for the

44th Aerospace Sciences Meeting and Exhibit

sponsored by the American Institute of Aeronautics and Astronautics

Reno, Nevada, January 9-12, 2006

National Aeronautics and

Space Administration

Glenn Research Center

Cleveland, Ohio 44135 


\section{Acknowledgments}

The author wishes to acknowledge the many team members who contributed to this project including: from Glenn Research Center, John Caruso, Amy Jankovsky, David Plachta, and Mike Skor (retired); Marshall Space Flight Center, Steve Tucker; Alpha Technologies, Leon Hostings; ARC, Jeff Felder, Lou Salerno, Pat Roach (retired); University of California, Peter Kittel; Goddard Space Flight Center, Mike Dipirro, (Wallops Island) Brian Hall; Johnson Space Flight Center, Eric Hurlbert; Kennedy Space Flight Center, William Notardenato; Langley Research Center, Pat Troutman, Dan Mazanek; Boeing, Al Olsen, Gary Grayson; Lockheed Martin, Bernard Kutter, Steve Salka; NCESR, Mohammed Kassemi, and Steve Barsi. My thanks goes out to a number of individuals too numerous to name here who provided support and technical advice to the formal project team members as well those who were kind enough to provide time and attention to coordinating such a complicated inter-NASACenter/industry effort.

Level of Review: This material has been technically reviewed by technical management.

Available from

NASA Center for Aerospace Information 7121 Standard Drive

Hanover, MD 21076-1320
National Technical Information Service 5285 Port Royal Road Springfield, VA 22161 


\title{
Flight Development for Cryogenic Fluid Management in Support of Exploration Missions
}

\author{
David J. Chato \\ National Aeronautics and Space Administration \\ Glenn Research Center \\ Cleveland, Ohio 44135
}

\begin{abstract}
This paper describes the results of the "Experimentation for the Maturation of Deep Space Cryogenic Refueling Technology" study. The purposes of this study were to identify cryogenic fluids management technologies requiring low gravity flight experiments to bring to technology readiness level (TRL) 5-6; to study many possible flight experiment options; and to develop near-term low-cost flight experiment concepts to mature core technologies of refueling. A total of twenty-five white papers were prepared in the course of this study. Each white paper is briefly summarized and relevant references cited. A total of 90 references are cited.
\end{abstract}

\section{Introduction}

Technologists have relied on flight tests to develop cryogenic fluid management technologies since the beginning of space travel. Drop tower, sounding rocket flights and subscale experiments carried on the Mercury missions provided vital information for the design of the Saturn IV and Centaur cryogenic upper stages. Information from these experiments and the subsequent full-scale demonstration flights successfully addressed the issues of propellant slosh, settling, and short-term storage/pressure control.

As a part of its technology suite the NASA Exploration Systems Research and Technology (ESR\&T) office commissioned the study "Experimentation for the Maturation of Deep Space Cryogenic Refueling Technology" abbreviated as MDSCR. Cryogenic refueling supports the ESR\&T mission by addressing the strategic technical challenges listed in table 1.

TABLE 1.-STRATEGIC TECHNICAL CHALLENGES (STC) ADDRESSED

\begin{tabular}{|l|l|l|}
\hline \multicolumn{1}{|c|}{ STC no. } & \multicolumn{1}{|c|}{ STC description } & \multicolumn{1}{c|}{ Project support or impact } \\
\hline 1 & Reusability & Refueling of propellants essential to reuse of propulsion stages \\
\hline 2 & Affordable logistics pre-positioning & $\begin{array}{l}\text { Refueling technologies required to make use of In-Situ Resource } \\
\text { produced cryogenic propellants }\end{array}$ \\
\hline 3 & Energy rich systems and missions & $\begin{array}{l}\text { High performance of cryogenic propellants essential to energy rich } \\
\text { systems and missions. Refueling technologies increase usability of } \\
\text { cryogenic propellants }\end{array}$ \\
\hline
\end{tabular}

The goals of MDSCR Project were: to identify cryogenic fluids management technologies requiring low gravity flight experiments to bring to technology readiness level (TRL) 5-6; to study many possible flight experiment options including sounding rockets, International Space Station, Shuttle-based experiments, low-cost free flying spacecraft, and re-flight of existing Shuttle/ISS experiments; and to develop near-term low-cost flight experiment concepts to mature core technologies of refueling.

The MDSCR project team was led by the Glenn Research Center at Lewis Field (GRC) and involved key members of other NASA centers as well as industry and academic partners. NASA centers playing a key role in this project included Ames Research Center (ARC), Goddard Space Flight Center (GSFC), Johnson Space Flight Center (JSC), Kennedy Space Flight Center (KSC), Langley Research Center (LaRC), and Marshall Space Flight Center (MSFC). Industry partnerships were formed with the Boeing Company and Lockheed Martin. The Case Western Reserve Universities National Center for Space Exploration also assisted. MDSCR supported the In-STEP Element Program within the Technology Maturation Program (TMP). 
An initial assessment of technologies (ref. 1) produced the list of technologies shown in table 2 Note however that the continuing investigation suggested several additional technologies to consider. These will be discussed later.

TABLE 2.-FLIGHT TESTING REQUIREMENTS OF CFM TECHNOLOGIES

\begin{tabular}{|c|c|c|c|c|}
\hline $\begin{array}{l}\text { CFM } \\
\text { TECHNOLOGY } \\
\text { ELEMENT }\end{array}$ & $\begin{array}{l}\text { CURRENT } \\
\text { TRL }\end{array}$ & $\begin{array}{l}\text { PAST 1-G } \\
\text { ACCOMPLISHMENTS }\end{array}$ & LOW-G ISSUES & $\begin{array}{l}\text { FLIGHT } \\
\text { TESTING }\end{array}$ \\
\hline $\begin{array}{l}\text { PASSIVE } \\
\text { STORAGE- }\end{array}$ & 5 & $\begin{array}{l}\text { *3 percent Loss/month } \\
\text { Demonstrated with Large } \\
\text { Scale LH2 Test }\end{array}$ & $\begin{array}{l}\text { Low-g thermal stratification } \\
\text { effects unknown }\end{array}$ & $\begin{array}{l}\text { Highly desirable } \\
\text { for stratification }\end{array}$ \\
\hline $\begin{array}{l}\text { ACTIVE STORAGE } \\
\text { (ZERO BOIL-OFF) }\end{array}$ & $\begin{array}{l}4 \mathrm{LO} 2 / \mathrm{CH} 4 \\
3 \mathrm{LH} 2\end{array}$ & $\begin{array}{l}\text { *Subscale demo with } \\
\text { LN2 and } 10 \mathrm{~W} \text { at } 97 \mathrm{~K} \\
\text { cryocooler } \\
\text { *Large scale demo with } \\
\text { commercial cryocooler }\end{array}$ & $\begin{array}{l}\text { Low-g thermal stratification } \\
\text { effects unknown }\end{array}$ & $\begin{array}{l}\text { Highly desirable } \\
\text { for stratification }\end{array}$ \\
\hline $\begin{array}{l}\text { PRESSURE } \\
\text { CONTROL }\end{array}$ & 4 & $\begin{array}{l}\text { *Large scale demo of } \\
\text { thermodynamic vent } \\
\text { system (TVS) with spray } \\
\text { bar } \\
\text { *Subscale test of TVS } \\
\text { with axial jet mixer }\end{array}$ & $\begin{array}{l}\text { Low-g heat transfer and fluid } \\
\text { dynamics effects mixing, de- } \\
\text { stratification and cycle rate }\end{array}$ & Highly desirable \\
\hline MASS GAUGING & 3 & $\begin{array}{l}\text { *Component testing with } \\
\text { simulant fluids, LN2 and } \\
\text { limited LH2 }\end{array}$ & $\begin{array}{l}\text { Some concepts strongly effected } \\
\text { by low-g heat transfer and fluid } \\
\text { behavior }\end{array}$ & Highly desirable \\
\hline $\begin{array}{l}\text { LIQUID } \\
\text { ACQUISITION }\end{array}$ & 3 & $\begin{array}{l}\text { *Bubble point testing } \\
\text { with LN2 } \\
\text { *Historical data (1960's) }\end{array}$ & $\begin{array}{l}\text { Low-g heat transfer significantly } \\
\text { effect LAD performance }\end{array}$ & Required \\
\hline FLUID TRANSFER & 3 & $\begin{array}{l}\text { *Subscale demo of } \\
\text { chill/no vent fill testing }\end{array}$ & $\begin{array}{l}\text { Transfer operation strongly } \\
\text { effected by low-g }\end{array}$ & Required \\
\hline
\end{tabular}

It was felt that early flight testing of these technologies would benefit the NASA exploration program. Early flight testing of liquid acquisition, mass gauging and pressure control technologies would enable the use in lowgravity (low-g) of cryogenic propellant in the 2012 Crew Exploration Vehicle (CEV). Early flight testing of fluid transfer technologies may enhance future missions by providing on-orbit assembly options for stages that cannot be launched in a single mission.

The MDSCR project was conducted as a series of research tasks. The first task was to review the prior literature for previous flight experiments, carriers, and launch systems. These were then documented in two page technical white papers. The second task was to conduct a technical assessment of current research by meeting with team members. Four technical assessment meetings were conducted covering the majority of research teams.

Unfortunately restrictions placed on the release of architecture studies prevented the inclusion of the results of the Langley and Johnson teams in this paper. The third task was to transform the findings of the technical assessments into white papers. These were added to the white papers accumulated in the first task. The fourth task was to convene the team to review the white papers produced in the prior task, and rank them on the basis of technical need, cost, return on investment and flight platform. Although the team has completed task four the evaluation results are still under review and will be reported at a later date. The fifth task was to prepare monthly reports to HQ as well as the final report. This task will be concluded by preparing the final report which should be forthcoming as a NASA TP in the near future.

\section{White Papers}

The one of the principal outputs of the MDSCR study was a series of technical "white papers." The objectives of the white papers were to:

- Provide quick reference summary of cryogenic fluids management experiment concepts

- Enable rapid review and comparison between experiment concepts

- Provide publishable documentation of the options explored by the research effort 
The following additional instructions were provided to the preparers;

- To be only concerned with technologies that are unique to "cryogens" or "space refueling"

- To highlight areas of flight test

- To provide a comprehensive bibliography

- To limit the paper to two pages of 10 point text (some exceptions were granted for this guidance)

The objectives were different than those of an ordinary white paper, which typically advocates a position rather than provides a technical review. What was required was something similar to a "case study" but much briefer to avoid being overwhelmed with detail.

A total of twenty-five white papers were prepared during the MDSCR study. To help organize the "white papers" they were separated into five groupings. The first grouping was "Carriers and Launchers" which talked about ways to provide access to low gravity without discussing specific experiments. The second grouping was "Experiments Historical" which discussed flight experiments which have already been completed. The third grouping was "Instrumentation" for instruments that would be helpful to experiment design, but were not complete experiments in themselves. The fourth grouping was "Experiments Proposed" for experiment concepts in design and development. The final grouping was "Maturation Strategies" These were broad statements of approach and philosophy to the maturation of cryogenic technologies without proposing specific experiments.

Space does not permit presentation of all the full white papers in this document. Instead the author has presented brief descriptions with citations to references on which the white papers are based. For the "Experiments Proposed" and "Maturation Strategies" which represent active concepts not yet in the technical literature, the description has been expanded to a paragraph and a key figure or illustration included. White paper descriptions by grouping follow bellow.

\section{A. Carriers and Launchers}

Brief descriptions only. Most of these carriers have a payload users manual references to provide detailed information.

\section{The Hitchhiker Shuttle Small Payloads Carrier (GSFC)}

This paper described the capabilities of the Hitchhiker bridge mounted in the shuttle cargo bay. This was the carrier used for both the SHOOT and VTRE experiments described in later white papers. Key references include (refs. 2 and 3)

\section{Pegasus Air Launch System (GSFC)}

This paper described the methodology used to fly cryogenic payloads such as Wide Field Infrared Explorer (WIRE) on the Pegasus Launch vehicle (refs. 4 and 5)

\section{NASA Sounding Rocket Program (GSFC)}

This paper summarized the capabilities and constraints of NASA's current stable of sounding rockets (refs. 6 and 7)

\section{Cryogenic Ground Serving/Launch Operations (KSC)}

This paper described current capabilities and methodologies for handling cryogens on current launch. Also included was a brief discussion of potential upgrades and handling of highly subcooled "densified" cryogens

5. Falcon Launch Vehicle Family (KSC)

This paper described a DARPA/Space X effort to provide very low cost launch vehicles (ref. 8)

\section{B. Experiments Historical}

Brief descriptions only. The reader is referred to the referenced published literature for details

\section{Aerobee Sounding Rocket Cryogenic Fluid Management Tests (GRC)}

A sounding rocket effort in the early sixties done with liquid hydrogen to understand the behavior of cryogens in low gravity (refs. 9 through 18 )

\section{Saturn IVB Fluid Management Qualification (GRC)}

Flight qualification of the techniques to handle cryogens for the Saturn rockets used to launch the Apollo missions to the moon (refs. 19 through 25) 


\section{Flight Qualification of Centaur CFM (GRC)}

Flight tests used to develop fluid management strategies for the Centaur upper stage (ref. 26)

4. Titan Centaur CFM Flight Tests (GRC)

Flight tests piggybacked on the Titan/Centaur mission to further develop cryogenic fluid management for the Centaur upper stage (refs. 27 through 29)

5. Vented Tank Resupply Experiment (GRC)

An experiment mounted in three Get Away Special canisters (GAS cans) attached to a cross bay Hitchhiker bridge to study the ability of vane propellant devices to control liquid during propellant transfer, tank venting, and boiling (ref. 30)

6. Tank Pressure Control Experiment (GRC)

A series of single GAS can experiments mounted on the shuttle cargo bay sidewall to study low gravity tank mixing, boiling and pressure control (refs. 31 through 35)

7. Storable Fluid Management Demonstration/Fluid Acquisition and Resupply Experiment SMFD/FARE Flight Experiments (GRC)

A series of shuttle middeck locker experiments to study vane and screen channel liquid acquisition devices. Room temperature water was used as test fluid. This limited the experiments to fluid dynamic effects only (refs. 36 through 39)

8. Capillary Flow Experiment (GRC)

A very small sub-scale experiment to study fundamentals of vane devices on space station. Launch on cargo mission provided quick turnaround as well as station access during the Columbia stand down. (refs. 40 through 41)

9. Cryogenic Liquid Acquisition Storage and Supply Experiment (JSC)

A cryogenic experiment side mounted on the shuttle cargo bay. This experiment was planned to support the replacement of the shuttle storable system with a non-toxic oxygen/ethanol propulsion system. Carried to the preliminary design phase only

10. Microgravity Science Support on the NASA Sounding Rocket Program

A history of recent NASA microgravity sounding rocket experiments

11. Superfluid Helium On-Orbit Transfer (Shoot) Flight Demonstration (GSFC)

An experiment to study the fluid management of superfluid helium. Flown on the shuttle Hitchhiker cross-bay bridge (refs. 42 through 54)

12. Cryogenic Propellant Depots (GRC)

A review of prior depot design efforts. Extensive references included (refs. 55 through 79)

\section{Instrumentation}

Brief description. Again please refer to the references for details

1. Cryogenic Flowmeters (JSC)

Ground tests of a series of potential cryogenic flowmeters. Done to support On-Orbit Resupply designs (ref. 80)

2. SHOOT Cryogenic Instrumentation Applicable to Cryogenic Depots (GSFC)

Instrumentation developed as part of the SHOOT program (refs. 43 and 81 through 90)

\section{Experiments Proposed}

These experiments are still in active development. As such detailed documentation is as yet unpublished. A paragraph description is provided for each to give the reader a more thorough description.

\section{ZBOT Experiment (NCESR/GRC)}

The overall objective of the ZBOT is to investigate the effectiveness of the Zero Boil-Off (ZBO) strategy as an innovative means for eliminating self-pressurization and mass loss in space cryogenic storage tanks based on an optimized and synergetic application of active heat removal and forced-mixing. The project involves performing a small scale ISS experiment to study tank pressurization and pressure control in microgravity. A layout of the ZBOT ISS hardware design using the ISS glovebox is shown in figure 1. The experimental work was to be supported by an extensive CFD modeling effort. The approach was to construct a detailed CFD model, validate it with small and large scale ground test data. Then the small scale on-orbit data would be used to assess the changes between small ground test and small scale flight test, the model re-validated for the small scale flight data and then used to predict large scale flight performance. The ISS experiment design has been place on hold at the preliminary design stage, but the modeling effort is still on-going. 


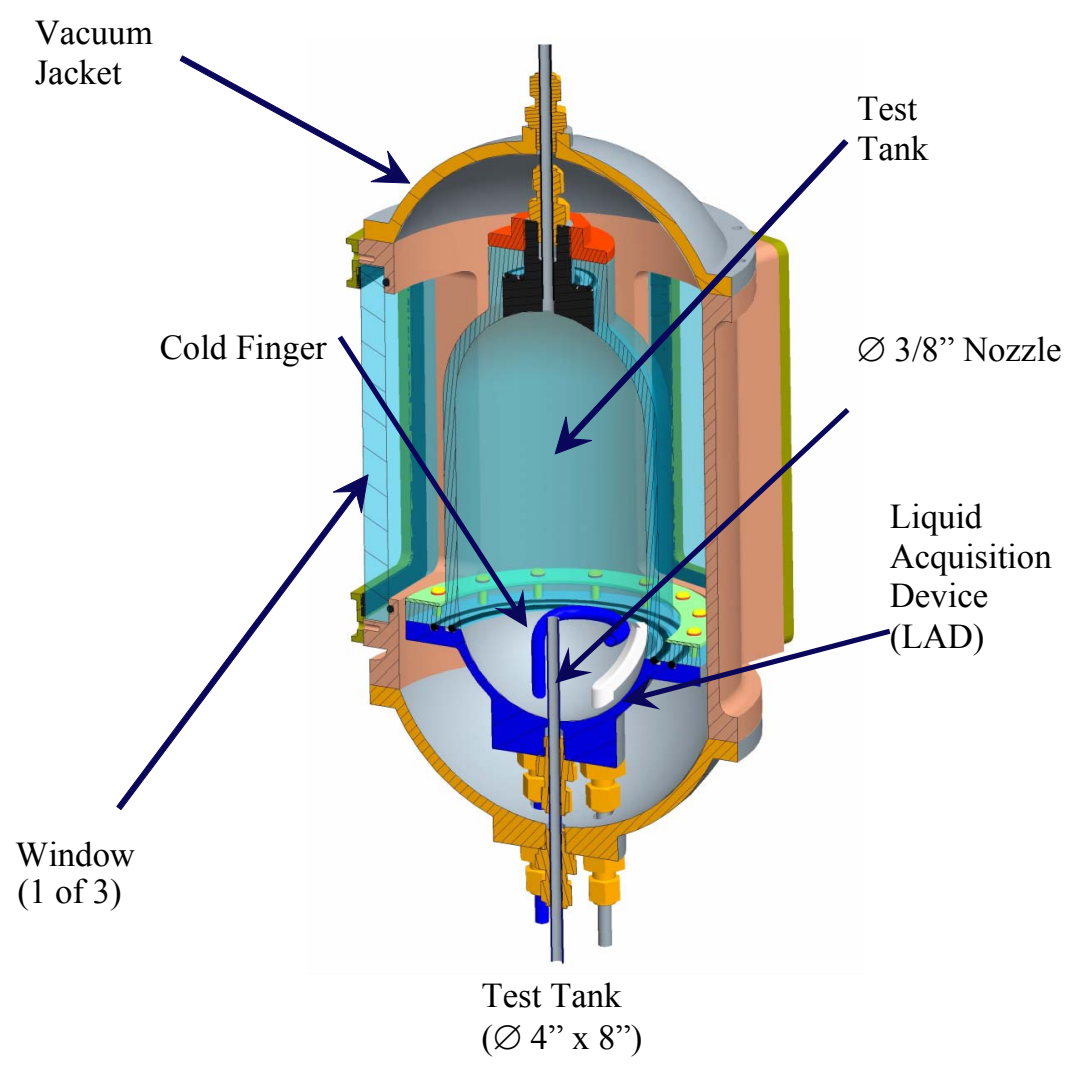

Figure 1.-ZBOT ISS hardware design details cutaway of test chamber.

\section{Centaur CTB (Lockheed Martin)}

The Lockheed Martin team provided a conceptual design for a small cryogenic experiment tank attached to the aft end of a Centaur stage. Figure 2 shows an artists concept of this tank. Note also below this tank a valve panel for the experiment as well. The proposed design attaches to existing hard points on the Centaur aft end and is isolated from the stage propulsion by pyrotechnic valves until after the primary Centaur mission is complete. As such the experiment can be integrated as a secondary payload on any Centaur launch with excess payload capacity with minimal impact to the primary payload. With such approaches the Centaur upper-stage vehicle can provide a low cost test platform for performing numerous flight demonstrations of the full breadth of required CFM technologies in a schedule supporting CEV development. 


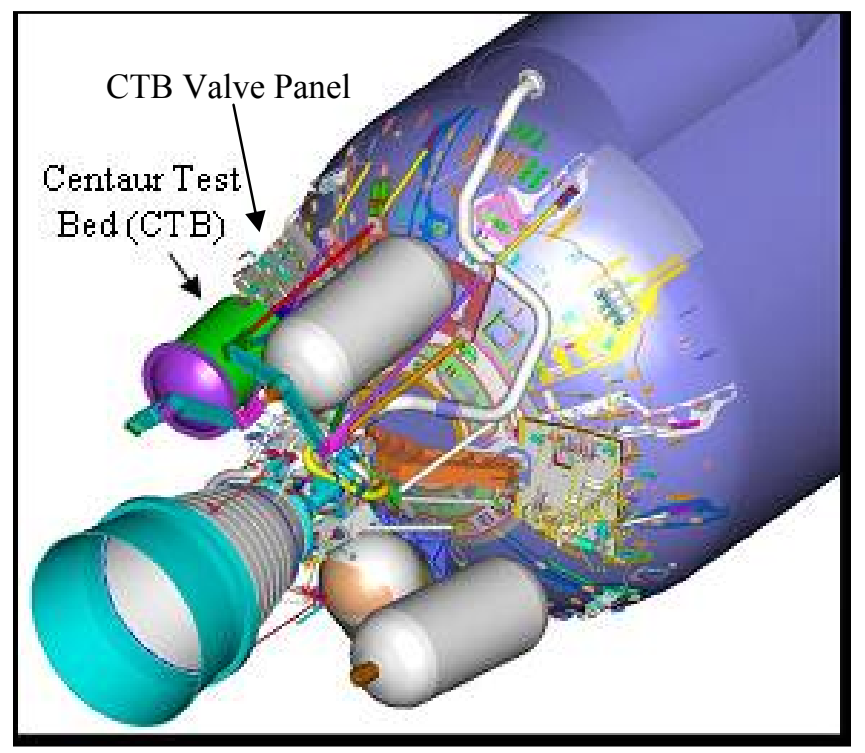

Figure 2.- The Centaur Test Bed (CTB) concept showing experimental tank mounted on Centaur Aft end.

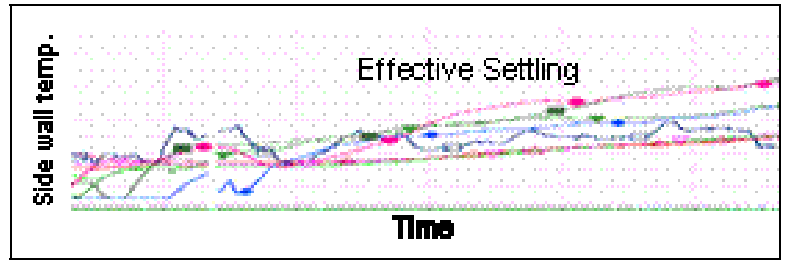

Figure 3.-Centaur has demonstrated effective propellant control at $10^{-5} \mathrm{G}$ 's.

\section{E. Maturation Strategies}

As stated previously these are broad statements of approach and philosophy to the maturation of cryogenic technologies without proposing specific experiments. Most are evolving as time progresses and missions change, but they do provide ideas and concepts for future ways forward. Space permits only a summary paragraph for each of the concepts in this paper.

\section{Settled Transfer (Lockheed Martin)}

Lockheed-Martin submitted this vision foe evolving from current upper stage cryogenic fluid management practices to a full on-orbit capability. For the exploration vision to be able to realize the huge benefit of cryogenic propellant transfer, one must ensure the reliability and robustness of the transfer process. To implement cryogenic transfer starting with the first lunar exploration mission requires the use of existing or nearly existing technology to maintain a reasonable development risk. Utilizing low acceleration during the cryogenic transfer operation significantly simplifies the entire operation, enabling the maximum use of existing, mature upper stage cryogenicfluid-management (CFM) techniques. With settling, large-scale propellant transfer becomes an engineering effort, not a technology development endeavor. The key technologies: propellant acquisition, hardware chilldown, pressure control, and mass gauging are all currently in use on Centaur and the Delta IV upper stage. The key remaining technology, rendezvous and docking, is required regardless of the use of propellant transfer. Figure 3 shows the results of settling test on the Centaur and shows control can be achieved even with only $10^{-5} \mathrm{~g}$ of settling.

\section{CFD Tools (Boeing)}

Boeing presented their vision for the correct role of both CFD modeling and flight experimentation (see ZBOT above for a similar plan of attack). Computational modeling tools for the design of cryogenic and low-gravity fluid space systems offers both development cost savings and improved designs. However, the tools and approaches 
employed must be quantitatively verified in relevant environments. It is recommended to develop and experimentally validate computational capabilities in several thermodynamic and fluid-dynamic areas of spacecraft propulsion design to reap the performance and financial benefits of these advanced modeling technologies.

\section{On Orbit CFM (Boeing)}

Boeing reviewed the baseline technology plan (see table 2) and provided their view of research they thought were important. Table 3 shows the Boeing recommendation of technologies to pursue versus the MDSCR baseline. For the most part Boeing is in agreement with the baseline. However they added elements for the development of incorporating Micro Meteoroid and Orbital Debris protection into the insulation system and reducing the thermal conductivity of multilayer insulation penetrations.

TABLE 3.-REVISED TECHNOLOGIES FOR MDSCR

\begin{tabular}{|c|c|c|c|}
\hline Technologies & NASA GRC ${ }^{1}$ & Boing/NASA MSFC ${ }^{74}$ & Post Flight Test TRL \\
\hline MLI & 5 & $\begin{array}{l}5 \text { (insulation thermal performance) } \\
4 \text { (insulation degradation in launch) } \\
5 \text { (atomic oxygen and contamination) }\end{array}$ & 7 \\
\hline VCS & 5 & $\begin{array}{l}5 \text { (performance) } \\
5 \text { (thermal performance) }\end{array}$ & 7 \\
\hline MMOD & N/A & $\begin{array}{l}3 \text { (material and thickness) } \\
3 \text { (performance) }\end{array}$ & 7 \\
\hline Instrumentation & N/A & N/A & 7 \\
\hline Low-k penetrations & N/A & 5 & 7 \\
\hline TVS & 4 & $\begin{array}{l}5 \text { (thermal performance) } \\
3 \text { (micro-g heat transfer from fluid) }\end{array}$ & 7 \\
\hline Mass gauging & 3 & $\begin{array}{l}4 \text { (performance) } \\
3 \text { (micro-g performance) }\end{array}$ & 7 \\
\hline Cryocoolers & $\begin{array}{l}4(\mathrm{LO} 2 / \mathrm{CH} 4) \\
3(\mathrm{LH} 2)\end{array}$ & $\begin{array}{l}4 \text { (thermodynamic efficiency and life) } \\
3 \text { (micro-g performance) }\end{array}$ & 7 \\
\hline Umbilicals & $\begin{array}{l}3 \\
\text { (fluid transfer) }\end{array}$ & $\begin{array}{l}3 \text { (fluid leakage, pressure drop) } \\
3 \text { (force and alignment requirements) } \\
3 \text { (thermal performance) }\end{array}$ & 7 \\
\hline PMD & 3 & $\begin{array}{l}3 \text { (residual fraction; flow vs. percent liquid) } \\
4 \text { (pressure drop; long-term use) }\end{array}$ & 7 \\
\hline
\end{tabular}

\section{4. $\quad$ Shuttle DTO (JSC)}

JSC submitted this paper describing the approach used to design and qualify the Space Shuttle propulsion system and how this could be applicable to a cryogenic system. There are certain aspects of a cryogenic propellant system design that can only be fully tested in zero-g. However, flying an in-space experiment for zero-g testing of propellant acquisition, gauging, and transfer is an expensive proposition. The experiment becomes in itself a spacecraft with propulsion, avionics, launch vehicle interfaces, analysis, and ground test etc. Another approach is to basically to do analysis, tests in 1-g, and limited simulated zero-G environment, and then to build and fly the full scale spacecraft. The mission is flown in manner as to not jeopardize vehicle or crew, but such that data on performance is gathered to accomplish specific Development Test Objectives. This DTO data on performance is then used to expand the flight envelope. The zero-g thermal environment would be the primary focus of in-space DTOs. The initial flights would be flown in a manner to minimize effects by either mixing the system using pumps or by virtue of the maneuvers. As the DTOs expanded the confidence in zero-g thermal operations unneeded hardware and maneuvers would be gradually eliminated. Acquisition, gauging, and transfer can be certified for flight on the ground, and operational data gathered with DTOs.

\section{Summary}

Although the MDSCR study is drawing to a close and ended a prematurely due to changing NASA priorities, It will leave a legacy of ideas for future researchers. A number of the white papers document historical experiments and approaches. They will prove valuable to future researchers and will be fully documented in the MDSCR final report. The commonality of approaches to CFD and technology maturation should give confidence when laying out future research efforts. Several white papers highlight new and novel concepts especially in the experiments proposed and maturation strategies groupings. These will serve as a head start for preparing experiments in the 
future. Already ideas from this effort are being adapted for use in the liquid oxygen/liquid methane advanced development for CEV. As NASA focus' moves on to Lunar and Mars exploration the results of MDSCR will provide a valuable reference for the design of the flight experiments required for those challenging missions.

\section{References}

1. Chato, D.J, "Low Gravity Issues of Deep Space Refueling," AIAA-2005-1148, January 2005.

2. 740-SPEC-008, "Hitchhiker Customer Accommodations and Requirements Specifications," can be downloaded from the following website: http://sspp.gsfc.nasa.gov/documents/index.html.

3. "Low gravity superfluid transfer can be done: the results of the SHOOT flight demonstration," Michael J. DiPirro, Peter J. Shirron, and James G. Tuttle, Proc. of SPIE vol. 2227, Cryogenic Optical Systems VI, (1994) 222.

4. "Pegasus Fact Sheet," Orbital Sciences Corp., www.orbital.com, FS002.02.

5. "Pegasus User's Guide," Orbital Sciences Corp., Release 5.0 (Aug/2000).

6. "Sounding Rocket Program Handbook," NASA/GSFC/WFF, Suborbital and Special Orbital Projects Directorate, Sounding Rockets Program Office, July 2001.

7. "Wallops Flight Facility Range User's Handbook-840-HDBK-0001G," NASA/GSFC/WFF, Suborbital and Special Orbital Projects Directorate, Range and Mission Management Office, Version G (12/2003).

8. Payload Users Guide-Falcon Launch Vehicle Rev. 2 October 2004 available at http://www.spacex.com.

9. R.H. Knoll, G.R. Smolak, and R.R. Nunamaker, "Weightless Experiments with Liquid Hydrogen in Aerobee Sounding Rockets; Uniform Radiant Heat Addition-Flight 1,”NASA TM X-484, 1962.

10. J.G. McArdle, R.C. Dillon, and D.A. Altmos, "Weightless Experiments with Liquid Hydrogen in Aerobee Sounding Rockets; Uniform Radiant Heat Addition—Flight 2,” NASA TM X-718, 1962.

11. R.R. Nunamaker, E.L. Corpas, and J.G. McArdle, "Weightless Experiments with Liquid Hydrogen in Aerobee Sounding Rockets; Uniform Radiant Heat Addition—Flight 3,” NASA TM X-872, 1963.

12. J.D. Regetz Jr., M.J. Conroy, and R.G. Jackson, "Weightless Experiments with Liquid Hydrogen in Aerobee Sounding Rockets; Nonuniform Radiant Heat Addition —Flight 4,” NASA TM X-873, 1964.

13. K.L. Abdalla, R.A. Flage, and R.G. Jackson, "Zero-gravity Performance of Ullage Control Surface with Liquid Hydrogen While Subject to Unsymmetrical Radiant Heating,” NASA TM X-1001, 1964.

14. J.C. Aydelott, E.L. Corpas, and R.P. Gruber, "Comparison of Pressure Rise in a Hydrogen Dewar for Homogeneous, Normal-Gravity Quiescent, and Zero-Gravity Conditions-Flight 7," NASA TM X-1006, 1964.

15. J.C. Aydelott, E.L. Corpas, and R.P. Gruber, "Comparison of Pressure Rise in a Hydrogen Dewar for Homogeneous, Normal-Gravity Quiescent, and Zero-Gravity Conditions-Flight 9," NASA TM X-1052, 1965.

16. K.L. Abdalla, T.C. Frysinger, and C.R. Andracchio, "Pressure Rise Characteristics for a Liquid Hydrogen Dewar for Homogeneous, Normal-Gravity Quiescent, and Zero-Gravity Tests," NASA TM X-1134, 1965.

17. J.C. Aydelott, "Normal Gravity Self-Pressurization of 9-in. $(23 \mathrm{~cm})$ Diameter Spherical Liquid Hydrogen Tankage," NASA TN D-4171, 1967.

18. J.C. Aydelott, "Effect of Gravity on Self-Pressurization of Spherical Liquid-Hydrogen Tankage," NASA TN D-4286, 1967.

19. Anonymous, "Saturn IB Liquid Hydrogen Orbital Experiment Definition," NASA TM X-53158.

20. F.E. Swalley, G.K. Platt, and L.J. Hastings, "Saturn V Low Gravity Fluid Mechanics Problems and their Investigation by Full-Scale Orbital Experiment," In Fluid Mechanics and Heat Transfer Under Low Gravity, Lockheed June 1965.

21. F.E. Swalley, W.D. Ward, and L.E. Toole, "Low Gravity Fluid Behavior and Heat Transfer Results from the S-IVB-203 Flight," In "Proceedings of the Conference on Long-Term Cryo-Propellant Storage in Space," Marshall Space Flight Center, 1966.

22. H.J. Buchanan and F.M. Bugg "Orbital Investigation of Propellant Dynamics in a Large Rocket Booster," NASA TN D-3968, 1967.

23. Anonymous, "Evaluation of AS-203 Low Gravity Orbital Experiment," Chrysler Corporation, January 1967.

24. R.G. Adams and B. Bynum, "Performance Characteristics of Liquid-Vapor Sensors Operating in a Reduced Gravity Environment,” NASA TM 53840. 
25. L.E. Toole and L.J. Hastings, "An Experimental Study of the Behavior of a Sloshing Liquid Subjected to a Sudden Reduction in Acceleration.

26. R.F. Lacovic, et. al., "Management of Cryogenic Propellants in a Full-Scale Orbiting Space Vehicle," NASA TN D-4571, 1968.

27. R.F. Lacovic, "Centaur Zero Gravity Coast and Engine Restart Demonstration on the Titan/Centaur (TC-2) Extended Mission," NASA TM X-71821, 1975.

28. R.F. Lacovic, "Thermodynamic Data Report for the Titan/Centaur TC-5 Extended Misssion.

29. R.F. Lacovic, "Propellant Management Report for the Titan/Centaur TC-5 Extended Mission," NASA TM X$73749,1977$.

30. D.J. Chato, D.J, and T.A. Martin, "Vented Tank Resupply Experiment-Flight Test Results," AIAA-97-2815, July 1997 NASA TM-10749.

31. Michael D. Bentz, "Tank pressure control in low gravity by jet mixing," NASA-CR-191012, March 1993.

32. M.D, Bentz, R.H Knoll, M.M. Hasan, C.S, Lin, "Low-g fluid mixing - Further results from the Tank Pressure Control Experiment," AIAA PAPER 93-2423, June 1993.

33. Mohammad M. Hasan, Chin S. Lin, Richard H. Knoll, and Michael D. Bentz, "Tank Pressure Control Experiment: Thermal Phenomena," NASA TP 3564, March 1996.

34. Michael D. Bentz, et. al., "Tank Pressure Control Experiment-Results of three space flights," AIAA Paper 97-2816, July 1997.

35. M.D. Bentz, et. al., "Tank Pressure Control Experiment-A Low-g Mixing Investigation," AIAA-90-2376.

36. Z. Kirkland, and J. Tegart, "On-Orbit Propellant Resupply Demonstration," AIAA-84-1342, June 1984.

37. J. Tegart, and Z. Kirkland, "On-Orbit Propellant Resupply Demonstration-Flight Test Results," AIAA-851233, July 1985.

38. S. Dominick, and S. Driscoll, "Fluid Acquisition and Resupply Experiment (FARE I) Flight Results," AIAA 93-2424, June 1993.

39. S. Dominick, and J. Tegart, "Orbital Test Results of a Vaned Liquid Acquisition Device," AIAA-94-3027, June 1994.

40. M.M. Weislogel, et. al., "The Capillary Flow Experiments: Handheld Fluids Experiments for the International Space Station,” AIAA-2004-1148, 2004.

41. M.M. Weislogel, et. al., "Preliminary Results from the Capillary Flow Experiment Aboard ISS: The Moving Contact Line Boundary Condition," AIAA-2005-1439, 2005.

42. Michael J. DiPirro, Peter J. Shirron, and James G. Tuttle, "Low gravity superfluid transfer can be done: the results of the SHOOT flight demonstration," Proc. of SPIE vol. 2227, Cryogenic Optical Systems VI, (1994) 222.

43. M.J. DiPirro, P.J. Shirron, and J.G. Tuttle, "On orbit superfluid transfer: preliminary results of the SHOOT Flight Demonstration," Cryogenics. 34 (1994) 349.

44. J.G. Tuttle, M.J. DiPirro, and P.J. Shirron, "Thermal stratification of liquid helium in the SHOOT dewars," Cryogenics. 34 (1994) 369.

45. P.J. Shirron and M.J. DiPirro, "Low gravity thermal stratification of liquid helium on SHOOT," Cryogenics 32, (1992) 159.

46. K.F. Weintz, M. Basci, and J. Uber, "SHOOT dewar support strap design and performance," Cryogenics 34 (1994) 357.

47. J.C. Shapiro and G.L. Villere, "Description of SHOOT command and monitoring system," Cryogenics 34 (1994) 407.

48. J.R. Maddocks and S.W. Van Sciver, "Characterizing He II flow through porous materials using counterflow data," Advances in Cryogenic Engineering 37 (1992) 89.

49. M.J. DiPirro and P.J. Shirron, "The SHOOT orbital operations," Cryogenics 32, (1992) 85.

50. H.J. Khan, M. Rhee, and O. Figueroa, "Characterization of gaseous helium jet dispersion to atmosphere," Cryogenics 32, (1992) 20.

51. J.A. Nissen, B. Maytal, and S.W. Van Sciver, "Pressure drop in the SHOOT superfluid helium acquisition system," Cryogenics 30, 211 (1990).

52. J.R. Maddocks and S.W. Van Sciver, "Pressure drop and He II flow through fine mesh screens," Cryogenics 29, 503 (1989).

53. J.C. Shapiro and F.A. Robinson, "Interactive remote control for an STS-based helium transfer demonstration," Proc. AIAA Conf. on Computers in Aerospace (1989) 696-704. 
54. T. Castellano, E. Raymond, J. Shapiro, F. Robinson, and D. Rosenthal, "Knowledge based and interactive control for the SHOOT project," NASA Ames Technical Report FIA-89-05-16-01, May, 1989, also published in Proc. of Goddard Conf. on Space Applications for Artificial Intelligence NASA Conf. Pub. No. 3033, (1989) 3-11.

55. D. Heald, Orbital Propellant Handling and Storage Systems Definition Study Final Report, vol. I, Contract NAS9-15640, General Dynamics, 1979 (Early GD study).

56. R. Corban, J. Aydelott, and D. Shultz, Space-Based Fuel Depot, LeRC, 1987.

57. On-Orbit Cryogenic Fuel Depot Study Approach, NASA LeRC 1987.

58. B. St. Germain, et. al., Tanker Argus: Re-supply for a LEO Cryogenic Propellant Depot, IAC-020V.P.10.

59. S. Borowski, L. Dudzinski, and M. McGuire, Bimodal Nuclear Thermal Rocket (NTR) Propulsion for PowerRich, Artificial Gravity Human Exploration Missions to Mars, IAA-01-IAA.13.3.05, 52nd International Astronautical Congress, Oct. 2001.

60. D. Fester, Propellant Transportation to Space Operations, Martin Marietta, AIAA-86-34969.

61. V. Heinz, Analysis of a Space-Based Fuel Station, MIT, AIAA-76-196.

62. Cryogenic On-orbit Liquid Depot-Storage, Acquisition and Transfer (COLD-SAT) Experiment Design and Feasibility Study, E. Kramer ed., NASA TP 3523, 1998.

63. J. Schuster, E. Russ, and J. Wachter, Cryogenic On-orbit Liquid Depot-Storage, Acquisition and Transfer (COLD-SAT) Feasibility Study Final Report, NASA CR 185249, 1990.

64. S. Potter, et. al., A Cryogenic Propellant Production Depot for Low Earth Orbit, International Space Development Conference, 2001.

65. J. Schuster, Large Capacity Cryopropellant Orbital Storage Facility, Cryogenic Fluid Management Technology Workshop, 1987.

66. J. Schuster, Long Term Storage Facility Systems Study, General Dynamics.

67. D. Heald, et. al., Orbital Propellant Handling and Storage Systems for Large Space Programs, vol. II, Final Report, General Dynamics, Contract NAS9-15305, 1978.

68. Stephenson, The Orbital Maneuvering Vehicle, Aerospace America, vol. 26, Nov. 1988, p. 24-26, 28.

69. Anonymous, Long Term Cryogenic Storage Facility Systems Study, Phase I-III Executive Summary, GDSSCRAD-88-004, General Dynamics Space Systems Division, 1988, NAS8-36612 (GD Storage Depot).

70. E. Cady, K. Dayton, and R. Hopkins, Fuel Systems Architecture Study, Task 4-Conceptual Design of a MiniDepot and Tanker for STV Top-Off Requirements, McDonnell Douglas, 1992.

71. T. VanOverbeke, Thermodynamic Vent System Test in a Low Earth Orbit Simulation, NASA/TM-2004213193.

72. Anonymous, "Revolutionary Aerospace Systems Concepts (RASC): Orbital Aggregation and space Infrastructure Systems (OASIS)," Final Report, NASA 2002.

73. R. Eberhardt, G. Cunnington, and W. Johns, Conceptual Design and Analysis of Orbital Cryogenic Liquid Storage and Supply Systems, NASA CR-165321, May 1981.

74. Anonymous, "Space Solar Power and Platform Technologies for In-Space Propellant Depots," Final Report, Nov. 2000, Boeing, NASA Contract NAS8-99140.

75. R. Eberhardt, W. Bailey, Orbital Fluid Servicing and Resupply Operations, NASA CR-180238, Martin Marietta, 1987.

76. Super Fluid Helium Tanker (SFHT) Study, NASA CR-172110, Martin Marietta, 1989.

77. S. Borowski and L. Dudzinski, "2001: A Space Odyssey" Revised-The Feasibility of 24 Hour Commuter Flights to the Moon Using NTR Propulsion with LUNOX Afterburners, NASA/TM-1998-208830.

78. M. DiPirro, Super Helium on Orbit Transfer (SHOOT), N87-21151.

79. M. Benning, et. al., Analysis, Design and Development of a Partial Hydrogen Reliquifier, Air Products, October 1972, NAS8-21203.

80. R.S. Baird, "Flowmeter Evaluation for On-orbit Operations," NASA Johnson Space Center, NASA TM 100465, August 1988.

81. P.J. Shirron, M.J. DiPirro, and J.G. Tuttle, "Flight performance of the SHOOT liquid acquisition devices," Cryogenics 34 (1994) 361.

82. M.J. DiPirro, "Liquid acquisition devices for superfluid helium transfer," Cryogenics 30, 193 (1990).

83. J.G. Tuttle, M.J. DiPirro, and P.J. Shirron, "Liquid/gas phase separators for the Superfluid Helium On-Orbit Transfer (SHOOT) project," Advances in Cryogenic Engineering 39 (1994) 121. 
84. P.J. Shirron, J.L. Zahniser, and M.J. DiPirro, "A liquid/gas phase separator for He-I and He-II," Advances in Cryogenic Engineering 37 (1992) 105.

85. A. Kashani, R.A. Wilcox, A.L. Spivak, D.E. Daney, and C.E. Woodhouse, "SHOOT flowmeter and pressure transducers," Cryogenics 30, 286 (1990).

86. M.J. DiPirro, P.J. Shirron, and J.G. Tuttle, "Mass gauging and thermometry on the Superfluid Helium OnOrbit Transfer Flight Demonstration," in Advances in Cryogenic Engineering 39 (1994) 129.

87. P.J. Shirron, J.G. Tuttle, and M.J. DiPirro, "Performance of discrete liquid helium/vapor and He-I/He-II discriminators," Advances in Cryogenic Engineering 39 (1994) 1105.

88. J.D. Siegwarth, R.O. Voth, and S.M. Snyder, "Liquid-vapor surface sensors for liquid nitrogen and hydrogen," Cryogenics 32, (1992) 236.

89. M.J. DiPirro, M.E. Schein, R.F. Boyle, O. Figueroa, D.A. Lindauer, D.C. McHugh, and P.J. Shirron, ”The SHOOT cryogenic components: testing and applicability to other flight programs," Proc. of SPIE vol. 1340, Cryogenic Optical Systems IV, 291 (1990).

90. G.E. McIntosh, D.S. Lombard, D.L. Martindale, and M.J. DiPirro, "Bayonet for superfluid helium transfer in space," Advances in Cryogenic Engineering 33, 885 (1988). 


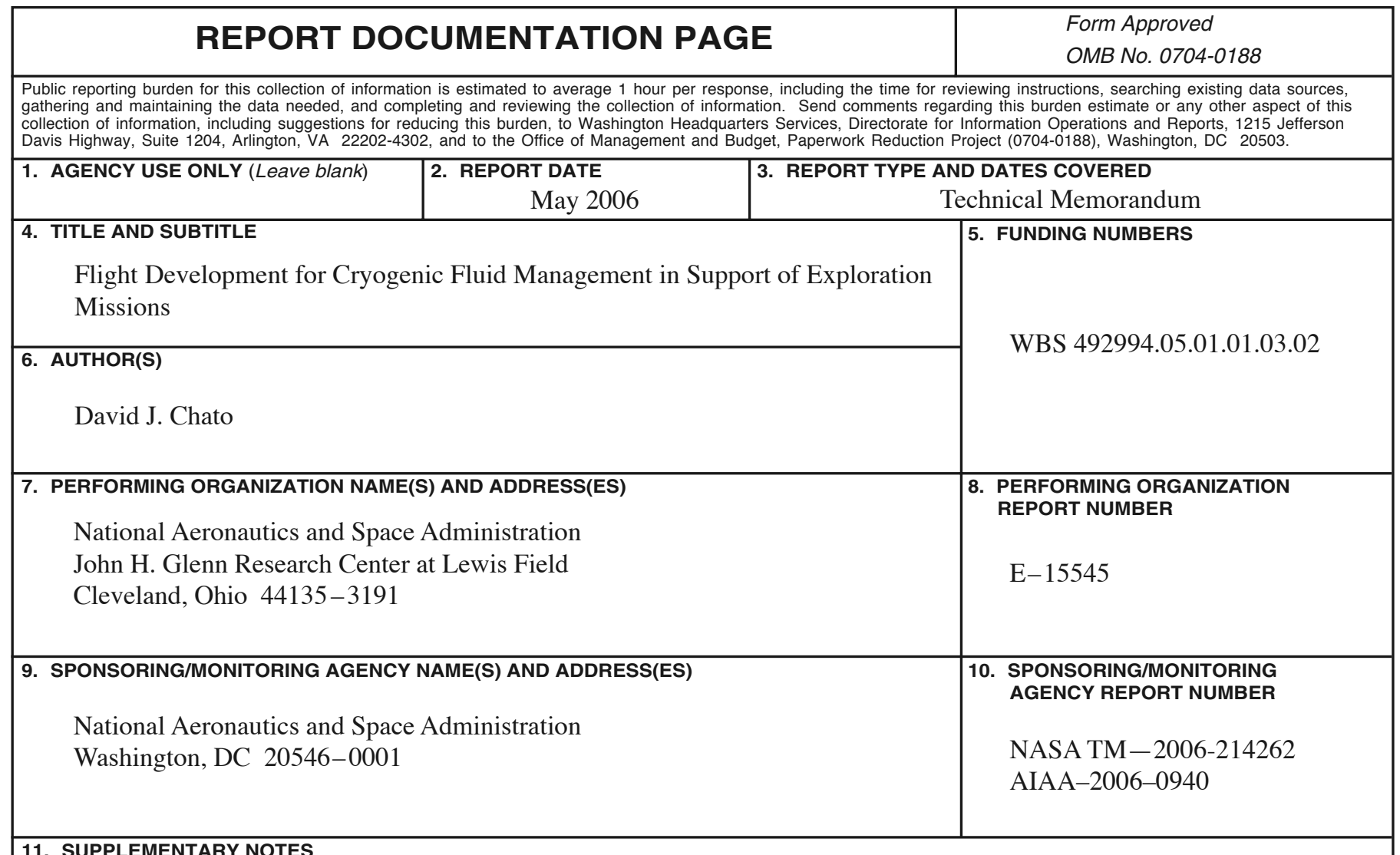

Prepared for the 44th Aerospace Sciences Meeting and Exhibit sponsored by the American Institute of Aeronautics and Astronautics, Reno, Nevada, January 9-12, 2006. Responsible person, David J. Chato, organization RTP,

216-433-7488.

\begin{tabular}{|l|l}
\hline 12a. DISTRIBUTION/AVAILABILITY STATEMENT & 12b. DISTRIBUTION CODE \\
Unclassified - Unlimited & \\
Subject Category: 34 & \\
Available electronically at http://gltrs.grc.nasa.gov & \\
This publication is available from the NASA Center for AeroSpace Information, 301-621-0390. &
\end{tabular}

13. ABSTRACT (Maximum 200 words)

This paper describes the results of the "Experimentation for the Maturation of Deep Space Cryogenic Refueling Technology" study. The purposes of this study were to identify cryogenic fluids management technologies requiring low gravity flight experiments to bring to technology readiness level (TRL) 5-6; to study many possible flight experiment options; and to develop near-term low-cost flight experiment concepts to mature core technologies of refueling. A total of twenty-five white papers were prepared in the course of this study. Each white paper is briefly summarized and relevant references cited. A total of 90 references are cited.

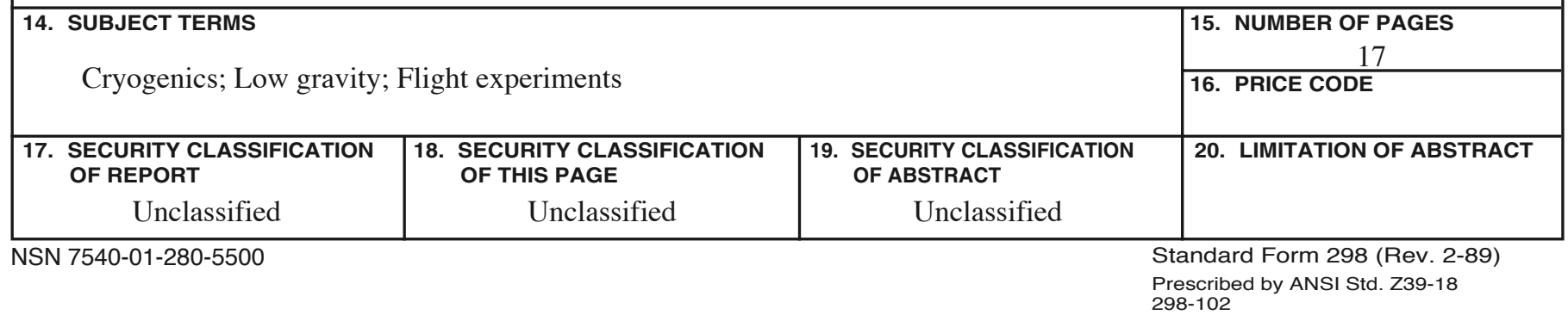



